JIC

16,1

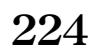

\title{
Intellectual capital in small and medium enterprises in Pakistan
}

\author{
Muhammad Khalique
}

Faculty of Economics and Business, Universiti Malaysia Sarawak, Kuching, Malaysia

Nick Bontis

DeGroote School of Business, McMaster University, Hamilton, Canada, and Jamal Abdul Nassir bin Shaari and Abu Hassan Md. Isa Faculty of Economics and Business, Universiti Malaysia Sarawak, Sarawak, Malaysia

\begin{abstract}
Purpose - The purpose of this paper is to evaluate the links between intellectual capital sub-components and organizational performance in small and medium enterprises (SMEs) operating in the electrical and electronics manufacturing sector in Pakistan.

Design/methodology/approach - Data were collected through structured questionnaires from a sample of 247 respondents from Pakistani SMEs in Gujranwala and Gujarat. Several tests were used to examine the reliability and validity of the research instrument. Finally, multiple regression analysis was used to test the proposed research hypotheses.

Findings - The findings of this study demonstrate that the overall regression model of intellectual capital shows goodness of fit while one component of intellectual capital - namely human capital - appeared insignificant. Subsequently, six out of seven research hypotheses was accepted.

Practical implications - This study will provide a valuable framework for entrepreneurs, executives, managers and policy makers in managing intellectual capital within the Pakistani context. Originality/value - To the best knowledge of the authors, this is the first empirical study that has been conducted on SMEs operating in the electrical and electronics manufacturing sector in Pakistan. Keywords Pakistan, Human capital, Small- to medium-sized enterprises, Intellectual capital,
\end{abstract} Organizational performance

Paper type Research paper

\section{Introduction}

Much of the extant intellectual capital literature has focussed on studying organizations in the developed world in nations such as the UK, USA, Canada, Australia and Sweden. Many academic researchers have conducted their studies within these developed economies and found that effective management of intellectual capital has a strong link with the success of organizations (Youndt and Snell, 2004; Ordonez de Pablos, 2004; Montequín et al., 2006; Kujansivu and Lönnqvist, 2007; Tovstiga and Tulugurova, 2007; De Castro and Sáez, 2008; St-Pierre and Audet, 2011). Due to the overwhelming acknowledgment of the positive role intellectual capital plays in the developed world, a burgeoning track of research has started to explore the concept of intellectual capital in small and medium enterprises (SMEs) operating in developing and under-developed economies. For example, Bontis et al. (2000) conducted their study in the Malaysian context and found that intellectual capital was a 